\title{
Pengaruh Umur Pindah Tanam Bibit dan Populasi Tanaman terhadap Hasil dan Kualitas Sayuran Pakcoy (Brassica campestris L., Chinensis group) yang Ditanam dalam Naungan Kasa di Dataran Medium
}

\author{
Ferry Firmansyah ${ }^{1}$, Tino M. Anngo² dan Aos M Akyas ${ }^{2}$ \\ ${ }^{1}$ Alumni Jurusan Budidaya Fakultas Pertanian Universitas Padjadjaran \\ ${ }^{2} J u r u s a n$ Budidaya Fakultas Pertanian Universitas Padjadjaran \\ Jalan Raya Jatinangor Km. 21 Bandung 40600 \\ Korespondensi: ferry_firmansyah@yahoo.com
}

\begin{abstract}
Effect of seedling transplanting age and plant populations on yield and quality of pakcoy (Brassica campestris L. Chinensis group) planted under screen-net in medium elevation
\end{abstract}

In tropical region, high light intensity and air temperature are significant problems in subtropical vegetables cultivation. In order to cultivate high-altitude vegetable in medium-altitude land, the use of screen-net as shading material could solve the problem. The objective of this experiment was to study the interaction effects between screen-net used as sun-shade and the cultivation techniques on growth, yield and quality of pakcoy, a highland vegetable, adapted in medium elevation. The experiment was set up in a Split Plot Design with two factors and three replications. A main plot was net shading and sub plots was combination cultivation technique comprised of seedling-transplanting age and plant populations. The results showed that an interaction effect between net shade and combined of cultivation techniques only significant on leaf area at harvest. Shading on plots with populations of 50 plants $\mathrm{m}^{-2}$ and seedling transplanting age either 2 or 3 weeks, produced larger leaf area than other treatments. The use of net shade reduced intensity of sunlight during the day for about $32 \%$ and days temperature about $2^{\circ} \mathrm{C}-3^{\circ} \mathrm{C}$. In this condition plant grown higher resulted in higher yield, higher percentage of marketable yield, and lighter green color of leaves. The treatments of 2 -week old seedling with population of 50 plants $\mathrm{m}^{-2}$ resulted more number of leaves. The plots planted with population of 50 plants $\mathrm{m}^{-2}$ resulted higher dry weight and at population of 100 plants $\mathrm{m}^{-2}$ have a higher yield.

Key words: Brassica camprestis, Pakcoy, Plant population, Screen-net, Seedling transplanting age.

\begin{abstract}
ABSTRAK
Di daerah tropis, intensitas cahaya dan suhu udara tinggi adalah masalah yang dihadapi pada budidaya sayuran introduksi dari daerah subtropis sehingga sayuran tersebut harus ditanam di dataran tinggi. Dalam usaha penanaman tanaman sayuran dataran tinggi di dataran medium, penaungan adalah salah satu usaha untuk mengatasi masalah tersebut. Percobaan ini bertujuan untuk mempelajari pengaruh interaksi dari naungan bahan kasa untuk memanipulasi faktor lingkungan dengan kultur teknik (umur pindah tanam bibit dan populasi tanaman) terhadap pertumbuhan, hasil, dan kualitas hasil tanaman pakcoy. Metode percobaan yang digunakan adalah Rancangan Petak Terbagi dengan dua faktor dan tiga ulangan. Petak utama adalah penggunaan naungan dan anak petak adalah kombinasi umur pindah tanam dan populasi tanaman. Hasil percobaan menunjukkan bahwa interaksi antara penggunaan naungan dan kombinasi teknik budidaya hanya terlihat pada luas
\end{abstract}


daun saat panen. Penggunaan naungan pada populasi 50 tanaman $\mathrm{m}^{-2}$ dengan umur bibit 2 dan 3 minggu menghasilkan luas daun yang lebih lebar dibandingkan perlakuan lainnya. Naungan kasa mampu menurunkan intensitas cahaya matahari pada siang hari sampai sekitar $32 \%$ dan berakibat pada penurunan suhu siang hari sekitar $2{ }^{\circ} \mathrm{C}-3{ }^{\circ} \mathrm{C}$. kondisi ini menyebabkan pertumbuhan tanaman lebih tinggi, hasil panen lebih banyak, persentase jumlah tanaman layak pasar lebih besar, serta warna hijau daun yang lebih cerah. Kombinasi umur bibit 2 minggu dan populasi 50 tanaman $\mathrm{m}^{-2}$, menghasilkan tanaman dengan jumlah daun lebih banyak. Pada pertanaman dengan populasi 50 tanaman $\mathrm{m}^{-2}$, bobot kering pupus dan akar lebih tinggi sedangkan dengan populasi 100 tanaman $\mathrm{m}^{-2}$ hasil panen lebih tinggi.

Kata kunci: Brassica camprestis, Pakcoy, Populasi tanaman, Screen-net, Umur pindah tanam bibit.

\section{PENDAHULUAN}

Pertumbuhan tanaman dipengaruhi oleh tiga faktor lingkungan. Faktor pertama adalah iklim yang meliputi suhu udara, radiasi sinar matahari, angin, dan kelembaban. Faktor kedua adalah tanah dan kandungan unsur hara yang ada pada tanah. Faktor ketiga adalah biotik, seperti gulma, hama, dan penyakit tanaman. Cahaya matahari merupakan sumber energi bagi tanaman dan merupakan salah satu unsur iklim yang memegang peranan penting dalam menentukan pertumbuhan dan perkembangan tanaman. Di daerah tropis seperti di Indonesia, intensitas cahaya dan suhu udara yang tinggi merupakan masalah yang banyak dihadapi dalam budidaya tanaman introduksi dari daerah subtropis (Basri, 1989; Akyas, 2000).

Sayuran introduksi yang kini banyak ditanam petani di Indonesia umumnya berasal dari daerah subtropis yang mempunyai hawa lebih sejuk dibandingkan di daerah tropis. Untuk penyesuaiannya, agar diperoleh pertumbuhan dan hasil yang baik, sayuran tersebut ditanam di dataran tinggi. Penanaman sayuran yang intensif di dataran tinggi sering dikatakan sebagai penyebab kerusakan tanah dan lingkungan (Adiyoga et al., 2001; Asandhi, 2000). Oleh karena itu, pemerintah sudah lama menyarankan usaha pengembangan tanaman sayuran dataran tinggi dialihkan ke dataran medium atau dataran rendah. Penanaman sayuran dataran tinggi di dataran medium akan menghadapi kendala terutama intensitas cahaya dan suhu udara yang tinggi yang menyebabkan respirasi dan transpirasi yang tinggi, sehingga pertumbuhan dan hasil tanaman menjadi rendah. Salah satu usaha yang dapat dilakukan untuk mengatasi hal ini adalah dengan penaungan.
Penaungan merupakan salah satu teknik dalam usaha perlindungan fisik bagi tanaman untuk memanipulasi faktor cuaca yang tidak menguntungkan perkembangan tanaman. Penaungan dengan kasa atau net banyak digunakan untuk melindungi tanaman yang peka terhadap intensitas cahaya matahari. Bahan naungan yang digunakan dan bentuk naungan berpengaruh terhadap perubahan faktor lingkungan yang terjadi. Bahan kasa (screennet ukuran 40 - 78 mesh) berwarna putih umumnya digunakan sebagai insect-net dan berperan pada sirkulasi udara pada modifikasi rumah kaca di daerah tropis (Ajwang \& Tantau, 2005). Ukuran net dan disain bangunan berpengaruh terhadap perubahan suhu udara dan kelembaban dalam bangunan tersebut (Harmanto et al., 2006; Ajwang \& Tantau, 2005; Campen, 2004).

Pada tanaman yang diperbanyak melalui benih dan memerlukan persemaian, pindah tanam sebaiknya dilakukan pada stadia tanaman yang tepat. Pindah tanam lebih dini akan mempercepat adaptasi tanaman terhadap lingkungan, sehingga pertumbuhan tanaman tidak terhambat dan dapat menghasilkan bagian vegetatif yang lebih baik. Jika pindah tanam terlambat, maka tanaman tidak mempunyai cukup waktu untuk menyelesaikan pertumbuhan vegetatifnya, tanaman lebih cepat menua dan cepat memasuki stadia generatif (Vavrina, 1998). Waktu pindah tanam yang tepat ditentukan, selain oleh jenis tanaman dan kultivar, juga ditentukan oleh kondisi lingkungan tempat tanaman dipindah tanamkan serta teknik budidayanya (Vavrina, 1998; Damanto et al., 1993). Penanaman dengan lingkugan terkendali di bawah naungan memungkinkan pemindahan tanaman lebih awal dibandingkan penanaman di lahan terbuka (Vavrina, 1998). 
Pengaturan jarak tanam atau populasi tanaman mempengaruhi tingkat kompetisi antartanaman terhadap faktor pertumbuhan. Jarak tanam yang rapat mengakibatkan tingkat kompetisi lebih tinggi, sehingga akan terdapat tanaman yang pertumbuhannya terhambat, baik karena ternaungi oleh tanaman sekitarnya ataupun karena kompetisi tanaman tersebut dalam mendapatkan air, unsur hara dan oksigen (Rachman, 2003). Persaingan yang terjadi pada kepadatan tanaman (populasi) tinggi adalah adanya kompetisi antar-tanaman itu sendiri (Mayadewi, 2007). Menurut Sitompul dan Guritno (1995), kuantitas faktor pertumbuhan yang diperoleh tanaman dalam selang waktu tertentu ditentukan oleh kekuatan kompetitifnya. Individu dengan daya kompetisi lebih besar akan tumbuh dengan lebih baik. Faktor lingkungan yang sesuai akan berpengaruh baik terhadap pertumbuhan tanaman yang berarti meningkatkan daya saing tanaman tersebut.

Pakcoy termasuk tanaman sayuran daun berumur pendek yang diintroduksi dari China. Saat ini pakcoy banyak diminati masyarakat, sehingga perlu pengembangan yang lebih luas antara lain ke dataran medium. Tujuan dari percobaan ini adalah mempelajari pengaruh kasa sebagai bahan naungan, dalam bentuk sungkup dan bentuk atap, untuk memanipulasi faktor lingkungan, serta mempelajari pengaruh interaksi penaungan tersebut dengan umur pindah tanam bibit dan populasi tanaman terhadap pertumbuhan, hasil, dan kualitas hasil tanaman pakcoy di dataran medium.

\section{BAHAN DAN METODE}

Percobaan dilaksanakan di Kebun Percobaan Fakultas Pertanian Universitas Padjadjaran Jatinangor, Sumedang, dari bulan Februari sampai April 2009. Lokasi percobaan terletak pada ketinggian 730 $\mathrm{m}$ di atas permukaan laut yang termasuk dataran medium, dan memiliki ordo tanah Inceptisol dengan tipe iklim $\mathrm{C}_{3}$ berdasarkan klasifikasi Oldeman.

Rancangan percobaan yang digunakan adalah Rancangan Petak Terbagi dengan dua faktor dan tiga ulangan. Petak utama adalah penggunaan naungan kasa $(\mathrm{N})$ dengan tiga taraf yaitu; tanpa naungan kasa (no), naungan kasa bentuk sungkup $\left(\mathrm{n}_{1}\right)$, naungan kasa bentuk atap (n2). Anak petak adalah kombinasi antara umur pindah tanam bibit dan populasi tanaman (P) dengan empat taraf yaitu; umur bibit 2 minggu setelah semai (MSS), populasi $100 \tan \mathrm{m}^{-2}\left(\mathrm{p}_{1}\right)$, umur bibit 2 MSS, populasi 50 tan $\mathrm{m}^{-2}\left(\mathrm{p}_{2}\right)$, umur bibit $3 \mathrm{MSS}$, populasi $100 \tan \mathrm{m}^{-2}\left(\mathrm{p}_{3}\right)$, umur bibit $3 \mathrm{MSS}$, populasi $50 \tan \mathrm{m}^{-2}\left(\mathrm{p}_{4}\right)$.

Benih pakcoy yang digunakan dalam percobaan ini adalah Pakcoy 15 Hibrida F1 dari PT Oriental Seed. Bahan naungan terbuat dari kasa plastik berwarna putih dengan kerapatan lubang 32 mesh. Lahan untuk bangunan penanaman berukuran $20 \mathrm{~m} \times 5 \mathrm{~m} \times 2.5 \mathrm{~m}$. Pada naungan bentuk sungkup lahan tersebut ditutup dengan kasa pada semua sisinya, sedang pada penaungan bentuk atap, hanya bagian atapnya saja yang ditutup dengan kasa, keempat dindingnya terbuka.

Penggunaan pupuk kompos dengan dosis 10 ton ha-1 dan pupuk NPK Phonska (15:15:15) dengan dosis $500 \mathrm{~kg} \mathrm{ha}^{-1}$ dilakukan 1 hari sebelum tanam. Pupuk susulan diberikan pada saat tanaman berumur 6 MSS dengan menggunakan pupuk NPK Mutiara (25:7:7), konsentrasi $5 \mathrm{~g} \mathrm{~L}^{-1}$, dengan cara dilarutkan, kemudian disiramkan pada tanaman.

Suhu, kelembaban, dan intensitas cahaya diukur setiap hari selama percobaan pada pukul 07.00, 12.00, dan 17.00 dengan alat Environment Tester (4 in 1) yang dapat mengukur kecepatan angin (anemometer), kelembaban udara (hygrometer sampai RH $80 \%$ ), suhu udara (thermometer $0-50$ $\left.{ }^{\circ} \mathrm{C}\right)$ dan intensitas cahaya (light meter).

Jumlah daun dan tinggi tanaman pakcoy dihitung setiap minggu mulai dari 4 MSS sampai 8 MSS. Luas daun serta berat kering pupus dan akar diamati pada 8 MSS. Hasil pakcoy diukur saat panen yaitu pada 8 MSS. Variabel kualitas hasil yang diukur meliput persentase tanaman layak pasar (LP) dan tidak layak pasar (TLP), bobot dan jumlah dari hasil pakcoy pada masing-masing tingkat kualitas serta warna hijau daun (metode CIE L*a*b*). Selain variabel cuaca, perbedaan angka rata-rata variabel yang diukur sebagai respons perlakukan dan interaksinya, diuji dengan uji $\mathrm{F}$ dan dilanjutkan dengan uji Jarak Berganda Duncan pada taraf $5 \%$.

\section{HASIL DAN PEMBAHASAN}

\section{Cuaca Harian Selama Percobaan}

Pada Gambar 1a, dapat dilihat bahwa penaungan dengan bahan kasa dapat menurunkan intensitas cahaya yang diterima tanaman terutama pada pagi dan siang hari sampai sekitar $32 \%$, sehingga cahaya yang diterima tanaman lebih rendah dibandingkan di lahan tanpa naungan. Penaungan ( $\mathrm{n}_{1}$ dan $\mathrm{n}_{2}$ ) dapat berimbas pada penurunan suhu udara $\left(2-3^{\circ} \mathrm{C}\right)$ di sekitar tanaman di dalam naungan tersebut (Gambar 1b.). Penaungan bentuk sungkup (n1) dapat lebih 
mempertahankan kelembaban udara daripada perlakuan lainnya karena sirkulasi udara di bawah naungan bentuk sungkup dapat tertahan (Gambar 1c). Kondisi di atas sesuai dengan hasil penelitian $\mathrm{Wu}$ et al. (2001) bahwa penaungan dengan bahan kasa dapat menurunkan intensitas cahaya matahari yang diterima tanaman dan dengan yang digambarkan oleh Harmanto et al. (2006) bahwa sirkulasi udara yang rendah dalam rumah plastik akan meningkatkan kelembaban udara relatif.

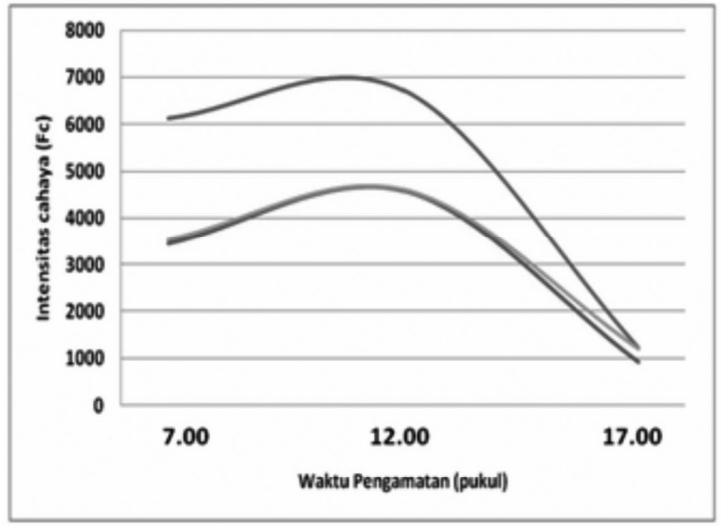

a

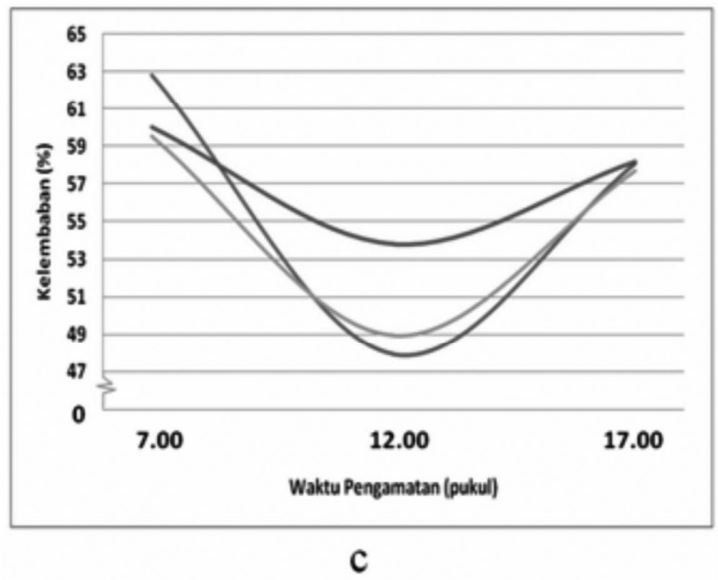

Pertumbuhan dan Hasil

Penaungan tidak mempengaruhi jumlah daun sedangkan perlakuan kombinasi teknik budidaya berpengaruh terhadap jumlah daun tanaman pada awal pertumbuhan (Tabel 1). Tanaman dengan perlakuan kombinasi umur bibit 2 MSS dengan populasi baik 100 tanaman $\mathrm{m}^{-2}$ maupun 50 tanaman $\mathrm{m}^{-2}$ ( $\mathrm{p}_{1}$ dan $\mathrm{p}_{2}$ ), memiliki jumlah daun lebih banyak daripada perlakuan kombinasi umur bibit 3 MSS pada kedua populasi. Hal ini memperlihatkan bahwa pemindahan bibit lebih lambat menyebabkan pertumbuhan tanaman terhenti (stagnasi). Namun pada pengamatan selanjutnya, yaitu pada umur tanaman 7 dan 8 MSS, hanya tanaman dengan perlakuan umur bibit 2 MSS dengan 50 tanaman $\mathrm{m}^{-2}$ yang memiliki jumlah daun lebih banyak dibandingkan kombinasi perlakuan lain. Pindah tanam lebih awal akan memberikan pertumbuhan

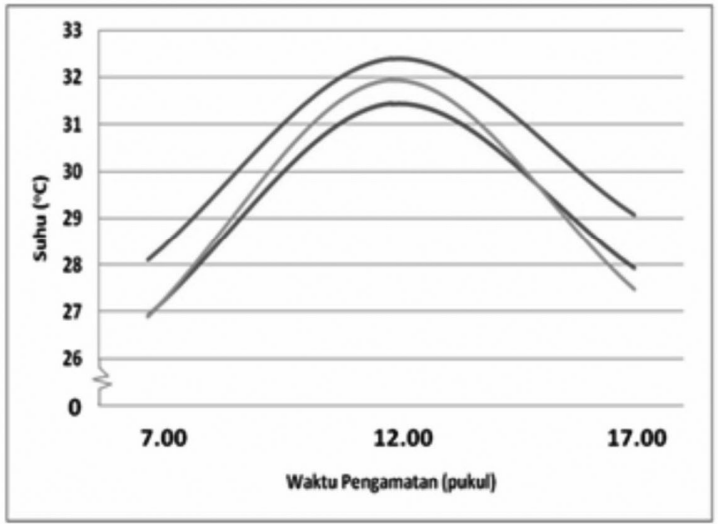

b

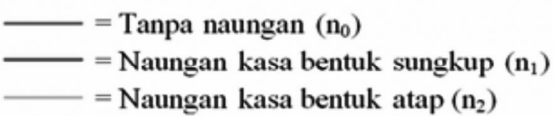

Gambar 1. Rata-rata intensitas cahaya (a), suhu udara (b) dan kelembaban (c) pada tiga waktu pengamatan padda kondi

vegetatif tanaman lebih baik dan tanaman tidak cepat menua (Vavrina, 1998). Populasi tanaman yang rapat berpengaruh pada penyerapan energi matahari oleh permukaan daun dan menentukan pertumbuhan tanaman. Kondisi daun yang saling menutupi dapat menyebabkan turunnya fotosintat yang dihasilkan dan berdampak pada lambatnya perkembangan daun (Gardner et al., 1991). 
Tabel 1. Jumlah daun pakcoy pada berbagai perlakuan naungan dan teknik budidaya

\begin{tabular}{|c|c|c|c|c|c|}
\hline \multirow{2}{*}{ Perlakuan } & \multicolumn{5}{|c|}{ Jumlah daun (helai) } \\
\hline & 4 MSS & 5 MSS & $6 \mathrm{MSS}$ & 7 MSS & $8 \mathrm{MSS}$ \\
\hline \multicolumn{6}{|l|}{ Naungan } \\
\hline no (Tanpa naungan) & 9,75 a & $12,72 \mathrm{a}$ & $16,78 \mathrm{a}$ & 20,32 a & $21,29 \mathrm{a}$ \\
\hline $\mathrm{n}_{1}$ (Sungkup kasa) & 9,86 a & $12,39 \mathrm{a}$ & $16,97 \mathrm{a}$ & $20,38 \mathrm{a}$ & $21,32 \mathrm{a}$ \\
\hline $\mathrm{n}_{2}$ (Atap kasa) & $9,32 \mathrm{a}$ & $11,60 \mathrm{a}$ & $16,54 \mathrm{a}$ & 19,88 a & $20,96 \mathrm{a}$ \\
\hline \multicolumn{6}{|l|}{ Teknik Budidaya } \\
\hline $\mathrm{p}_{1}\left(2 \mathrm{MSS}, 100 \tan \mathrm{m}^{-2}\right)$ & $10,50 \mathrm{~b}$ & $12,59 \mathrm{~b}$ & $16,91 \mathrm{~b}$ & $19,44 \mathrm{a}$ & 20,33 a \\
\hline $\mathrm{p}_{2}\left(2 \mathrm{MSS}, 50 \tan \mathrm{m}^{-2}\right)$ & $10,78 \mathrm{~b}$ & $13,48 \mathrm{~b}$ & $18,69 \mathrm{c}$ & $23,13 b$ & $23,96 \mathrm{~b}$ \\
\hline p3 $\left(3 \mathrm{MSS}, 100 \tan \mathrm{m}^{-2}\right)$ & 8,89 a & $11,39 \mathrm{a}$ & $15,54 \mathrm{a}$ & $18,81 \mathrm{a}$ & 19,89 a \\
\hline $\mathrm{p}_{4}\left(3 \mathrm{MSS}, 50 \tan \mathrm{m}^{-2}\right)$ & $8,41 \mathrm{a}$ & $11,48 \mathrm{a}$ & $15,93 \mathrm{a}$ & 19,37 a & 20,57 a \\
\hline
\end{tabular}

Keterangan: Angka-angka yang ditandai dengan huruf yang sama pada setiap kolom tidak berbeda nyata menurut Uji Jarak Berganda Duncan pada taraf nyata 5\%.

Tabel 2. Tinggi tanaman pakcoy pada berbagai perlakuan naungan dan teknik budidaya

\begin{tabular}{|c|c|c|c|c|c|}
\hline \multirow{2}{*}{ Perlakuan } & \multicolumn{5}{|c|}{ Tinggi tanaman $(\mathrm{cm})$} \\
\hline & $4 \mathrm{MSS}$ & $5 \mathrm{MSS}$ & $6 \mathrm{MSS}$ & $7 \mathrm{MSS}$ & $8 \mathrm{MSS}$ \\
\hline \multicolumn{6}{|l|}{ Naungan } \\
\hline no (Tanpa naungan) & $12,54 \mathrm{a}$ & $18,62 \mathrm{a}$ & $21,62 \mathrm{a}$ & $22,77 \mathrm{a}$ & $23,50 \mathrm{a}$ \\
\hline $\mathrm{n}_{1}$ (Sungkup kasa) & $14,57 \mathrm{~b}$ & $21,14 \mathrm{~b}$ & $23,10 \mathrm{~b}$ & $24,58 \mathrm{~b}$ & $25,31 b$ \\
\hline $\mathrm{n}_{2}$ (Atap kasa) & $14,05 \mathrm{~b}$ & $20,22 \mathrm{ab}$ & $23,30 \mathrm{c}$ & $24,24 \mathrm{~b}$ & $24,97 \mathrm{~b}$ \\
\hline \multicolumn{6}{|l|}{ Teknik Budidaya } \\
\hline $\mathrm{p}_{1}\left(2 \mathrm{MSS}, 100 \tan \mathrm{m}^{-2}\right)$ & $16,45 \mathrm{~b}$ & $19,96 \mathrm{ab}$ & 21,87 a & 23,46 a & $24,21 \mathrm{a}$ \\
\hline $\mathrm{p}_{2}\left(2 \mathrm{MSS}, 50 \tan \mathrm{m}^{-2}\right)$ & $15,42 \mathrm{~b}$ & $20,71 \mathrm{~b}$ & 23,14 a & 24,12 a & $24,85 \mathrm{a}$ \\
\hline $\mathrm{p}_{3}\left(3 \mathrm{MSS}, 100 \tan \mathrm{m}^{-2}\right)$ & $11,97 \mathrm{a}$ & $20,07 \mathrm{ab}$ & $22,54 \mathrm{a}$ & $23,71 \mathrm{a}$ & $24,45 \mathrm{a}$ \\
\hline $\mathrm{p}_{4}\left(3 \mathrm{MSS}, 50 \tan \mathrm{m}^{-2}\right)$ & $11,06 \mathrm{a}$ & $19,23 \mathrm{a}$ & 23,16 a & $24,15 \mathrm{a}$ & $24,87 \mathrm{a}$ \\
\hline
\end{tabular}

Keterangan: Angka-angka yang ditandai dengan huruf yang sama pada setiap kolom tidak berbeda nyata menurut Uji Jarak Berganda Duncan pada taraf nyata 5\%.

Dengan penaungan ( $\mathrm{n}_{1}$ dan $\left.\mathrm{n}_{2}\right)$, umumnya tinggi tanaman lebih tinggi daripada tanpa naungan (no), tidak terlihat perbedaan pengaruh antara naungan bentuk sungkup dan bentuk atap terhadap tinggi tanaman ini (Tabel 2). Intensitas cahaya matahari tinggi dapat menekan pertumbuhan tinggi tanaman, sebaliknya intensitas cahaya matahari rendah menyebabkan ruas memanjang dan sampai batas tertentu menyebabkan tanaman etiolasi. Namun penggunaan naungan kasa perlu disesuaikan dengan tingkat toleransi tanaman terhadap naungan (Wu et al., 2001).

Kombinasi teknik budidaya antara populasi dan umur bibit hanya berpengaruh pada tinggi tanaman di awal pertumbuhan tanaman (4 MSS dan 5 MSS). Tanaman dengan perlakuan umur bibit 2
MSS tumbuh dengan baik karena tanaman cepat beradaptasi terhadap lingkungan, sedangkan perlakuan umur bibit 3 MSS mengalami stagnasi sehingga tanaman terhambat pertumbuhannya. Ketika tanaman berumur 5 MSS pada populasi renggang, umur bibit dini ( $\left.\mathrm{p}_{2}\right)$ menjadikan tanaman tumbuh lebih baik daripada umur bibit yang lebih tua (p4), tetapi pada populasi rapat, umur bibit tidak berpengaruh ( $\mathrm{p}_{1}$ dan $\mathrm{p}_{3}$ ). Selanjutnya pada umur tanaman 6 MSS sampai dengan 8 MSS tidak ada perbedaan tinggi tanaman karena pertumbuhan tanaman dengan umur bibit 3 MSS telah pulih dan menyamai pertumbuhan tanaman dengan umur bibit 2 MSS.

Pengaruh interaksi antara perlakuan penaungan dan kombinasi teknik budidaya nyata 
Tabel 3. Interaksi antara naungan dan teknik budidaya terhadap luas daun terlebar pakcoy pada 8 MSS.

\begin{tabular}{|c|c|c|c|c|}
\hline \multirow{2}{*}{ Perlakuan } & \multicolumn{4}{|c|}{ Teknik budidaya } \\
\hline & $\mathrm{p}_{1}$ & $\mathrm{p}^{2}$ & $\mathrm{p}_{3}$ & $\mathrm{p}_{4}$ \\
\hline & \multicolumn{4}{|c|}{----------------------------------- $\mathrm{cm}^{2}{ }^{2}--------------------------------------$} \\
\hline \multirow[t]{2}{*}{ no (Tanpa naungan) } & 53,65 a & $63,84 \mathrm{a}$ & 60,79 a & 52,93 a \\
\hline & A & A & A & A \\
\hline \multirow[t]{2}{*}{ n1 (Sungkup kasa) } & 61,57 a & 83,99 a & $68,36 \mathrm{a}$ & $92,94 \mathrm{~b}$ \\
\hline & A & $\mathrm{BC}$ & $\mathrm{AB}$ & $\mathrm{C}$ \\
\hline \multirow[t]{2}{*}{$\mathrm{n}_{2}$ (Atap kasa) } & 40,49 a & 72,97 a & $56,00 \mathrm{a}$ & $90,04 \mathrm{~b}$ \\
\hline & A & $\mathrm{BC}$ & $\mathrm{AB}$ & $\mathrm{C}$ \\
\hline
\end{tabular}

Keterangan: Angka-angka yang ditandai dengan huruf kecil yang sama ke arah vertikal dan huruf kapital yang sama ke arah horizontal tidak berbeda nyata menurut Uji Jarak Berganda Duncan pada taraf nyata $5 \%$. $\mathrm{p}_{1}=2 \mathrm{MSS}, 100 \tan \mathrm{m}^{-2}, \mathrm{p}_{2}=2 \mathrm{MSS}, 50 \tan \mathrm{m}^{-2}, \mathrm{p}_{3}=3 \mathrm{MSS}, 100 \tan \mathrm{m}^{-2}, \mathrm{p}_{4}=3 \mathrm{MSS}, 50$ $\tan \mathrm{m}^{-2}$

Tabel 4. Bobot kering pupus dan akar per tanaman pakcoy pada berbagai perlakuan naungan dan teknik budidaya pada umur 8 MSS

\begin{tabular}{ccc}
\hline \multicolumn{1}{c}{ Perlakuan } & Bobot kering pupus $(\mathrm{g})$ & Bobot kering akar $(\mathrm{g})$ \\
\hline Naungan & & \\
\hline no (Tanpa naungan) & $43,58 \mathrm{a}$ & $9,75 \mathrm{a}$ \\
n1 (Sungkup kasa) & $46,67 \mathrm{a}$ & $8,33 \mathrm{a}$ \\
n2 (Atap kasa) & $43,50 \mathrm{a}$ & $8,50 \mathrm{a}$ \\
\hline Teknik Budidaya & & $8,00 \mathrm{a}$ \\
\hline p1 (2 MSS, $\left.100 \tan \mathrm{m}^{-2}\right)$ & $35,00 \mathrm{a}$ & $10,56 \mathrm{~b}$ \\
p2 (2 MSS, $\left.50 \tan \mathrm{m}^{-2}\right)$ & $54,78 \mathrm{~b}$ & $7,78 \mathrm{a}$ \\
p3 (3 MSS, $\left.100 \tan \mathrm{m}^{-2}\right)$ & $39,22 \mathrm{a}$ & $9,50 \mathrm{~b}$ \\
p4 (3 MSS, $\left.50 \tan \mathrm{m}^{-2}\right)$ & $49,33 \mathrm{~b}$ & \\
\hline
\end{tabular}

Keterangan: Angka-angka yang ditandai dengan huruf yang sama pada setiap kolom tidak berbeda nyata menurut Uji Jarak Berganda Duncan pada taraf nyata 5 \%.

terhadap luas daun saat panen (Tabel 3). Pada penggunaan penaungan (baik bentuk sungkup maupun bentuk atap), luas daun nyata lebih besar pada populasi renggang (50 tan $\mathrm{m}^{-2}$ ) dibandingkan pada populasi rapat. Pengaruh interaksi perlakuan naungan hanya terlihat pada perlakuan umur bibit 3 MSS dan populasi 50 tanaman $\mathrm{m}^{-2}\left(\mathrm{p}_{4}\right)$, pada penggunaan naungan, luas daun lebih besar dibandingkan pada lahan terbuka.

Suhu udara yang lebih tinggi karena intensitas cahaya yang lebih tinggi pada perlakuan tanpa penaungan (no) menyebabkan daun lebih sempit untuk mencegah respirasi yang tinggi, sehingga luas daun pada semua perlakuan kombinasi teknik budidaya (P) di lahan terbuka tidak berbeda. Sedangkan pada penaungan ( $\mathrm{n}_{1}$ dan $\mathrm{n}_{2}$ ), tanaman pada semua perlakuan umur bibit mempunyai luas daun yang lebih sempit pada populasi rapat dibandingkan populasi renggang. Hal ini menunjukkan bahwa umur bibit tidak berpengaruh terhadap luas daun. Namun populasi renggang mempunyai tingkat kompetisi antar tanaman rendah sehingga daun lebih lebar karena ruang tumbuh lebih besar.

Penaungan tidak mempengaruhi bobot kering pupus dan berat kering akar, sedangkan umur pindah tanam bibit dan populasi tanaman mempengaruhi baik bobot kering pupus maupun bobot kering akar (Tabel 4). Bobot kering menggambarkan penimbunan hasil asimilasi $\mathrm{CO}_{2}$ sepanjang musim pertumbuhan. Faktor utama yang mempengaruhi bobot kering total adalah radiasi matahari yang diabsorbsi dan efisiensi pemanfaatan energi tersebut untuk fiksasi $\mathrm{CO}_{2}$ (Gardner et al., 1991). Lahan tanpa penaungan memiliki intensitas cahaya yang lebih tinggi untuk fotosintesis, akan 
tetapi suhu tinggi pada perlakuan tanpa penaungan juga mengakibatkan penggunaan karbohidrat yang tinggi untuk proses respirasi untuk mendapatkan energi. Oleh karena itu, pengaruh tanpa penaungan terhadap bobot kering pupus maupun akar berbeda dengan penggunaan naungan. Teknik budidaya mempengaruhi bobot kering pupus (Tabel 4). Perlakuan dengan populasi renggang ( $\mathrm{p}_{2}$ dan $\mathrm{p}_{4}$ ) meningkatkan bobot kering pupus maupun akar. Pada populasi renggang, kompetisi rendah sehingga tanaman tumbuh lebih dan selanjutnya bobot kering yang lebih tinggi. Penaungan ( $\mathrm{n}_{1}$ dan $\mathrm{n}_{2}$ ) dapat meningkatkan hasil pakcoy (Tabel 5) karena suhu yang lebih rendah dan kelembaban yang lebih tinggi daripada tanpa naungan (Gambar 1). Selain itu, penaungan meningkatkan luas daun.

Untuk tanaman sayuran daun, pertumbuhan vegetatif yang terhambat akan menurunkan hasil panen. Hasil tanaman dengan kerapatan populasi 100 $\tan \mathrm{m}^{-2}$ dan umur bibit baik 2 MSS ( $\mathrm{p}_{1}$ ) maupun 3 MSS (p3) lebih tinggi, berarti populasi rapat lebih meningkatkan hasil dibandingkan dengan populasi renggang. Namun, perlakuan populasi rapat menghasilkan tanaman dengan bobot kering lebih rendah (Tabel 4). Populasi 100 tanaman $\mathrm{m}^{-2}$ menyebabkan ukuran pakcoy lebih kecil, tetapi belum melewati batas populasi yang dapat menyebabkan penurunan hasil per satuan luas.
Tabel 5.Hasil pakcoy pada berbagai perlakuan pada berbagai perlakuan naungan dan teknik budidaya

\begin{tabular}{lc}
\hline Naungan & Hasil $\left(\mathrm{kg} \mathrm{m}^{-2}\right)$ \\
\hline no (Tanpa naungan) & $4,36 \mathrm{a}$ \\
n1 (Sungkup kasa) & $6,75 \mathrm{~b}$ \\
n2 (Atap kasa) & $5,08 \mathrm{ab}$ \\
\hline Teknik Budidaya & \\
\hline p1 (2 MSS, $\left.100 \tan \mathrm{m}^{-2}\right)$ & $5,84 \mathrm{~b}$ \\
p2 (2 MSS, $\left.50 \tan \mathrm{m}^{-2}\right)$ & $4,80 \mathrm{a}$ \\
p3 (3 MSS, $\left.100 \tan \mathrm{m}^{-2}\right)$ & $5,92 \mathrm{~b}$ \\
p4 (3 MSS, $\left.50 \tan \mathrm{m}^{-2}\right)$ & $5,01 \mathrm{ab}$ \\
\hline
\end{tabular}

Keterangan: Angka-angka yang ditandai dengan huruf yang sama pada setiap kolom tidak berbeda nyata menurut Uji Jarak Berganda Duncan pada taraf nyata 5\%.

\section{Kualitas Hasil}

Penaungan tidak mempengaruhi persentase bobot layak pasar (LP) dan tidak layak pasar (TLP), tetapi mempengaruhi persentase jumlah LP dan TLP (Tabel 6). Jika persentase bobot sama tetapi persentase jumlah tanaman berbeda, maka ukuran tanaman berbeda. Tanaman layak pasar pada perlakuan naungan bentuk sungkup berbobot lebih kecil daripada perlakuan tanpa naungan, tetapi tidak berbeda dengan tanaman pada perlakuan naungan

Tabel 6. Persentase tanaman Layak Pasar (LP) dan Tidak Layak Pasar (TLP) dari hasil pakcoy pada berbagai perlakuan naungan dan teknik budidaya

\begin{tabular}{|c|c|c|c|c|}
\hline Perlakuan & $\begin{array}{c}\text { Bobot TLP } \\
(\%)\end{array}$ & $\begin{array}{c}\text { Bobot LP } \\
(\%)\end{array}$ & $\begin{array}{c}\text { Jumlah TLP } \\
(\%)\end{array}$ & $\begin{array}{c}\text { Jumlah LP } \\
(\%)\end{array}$ \\
\hline \multicolumn{5}{|l|}{ Naungan } \\
\hline no (Tanpa naungan) & $59,35 \mathrm{a}$ & $40,65 \mathrm{a}$ & $75,56 \mathrm{~b}$ & $24,44 \mathrm{a}$ \\
\hline $\mathrm{n}_{1}$ (Sungkup kasa) & 38,97 a & $61,03 \mathrm{a}$ & 30,47 a & $69,53 \mathrm{~b}$ \\
\hline $\mathrm{n}_{2}$ (Atap kasa) & 49,31 a & 50,69 a & $51,28 \mathrm{ab}$ & $48,72 \mathrm{ab}$ \\
\hline \multicolumn{5}{|l|}{ Teknik Budidaya } \\
\hline $\mathrm{p}_{1}\left(2 \mathrm{MSS}, 100 \tan \mathrm{m}^{-2}\right)$ & $60,46 \mathrm{a}$ & $39,54 \mathrm{a}$ & $56,80 \mathrm{a}$ & $43,20 \mathrm{a}$ \\
\hline $\mathrm{p}_{2}\left(2 \mathrm{MSS}, 50 \tan \mathrm{m}^{-2}\right)$ & $49,22 \mathrm{a}$ & $50,78 \mathrm{a}$ & $51,37 \mathrm{a}$ & $48,63 \mathrm{a}$ \\
\hline $\mathrm{p}_{3}\left(3 \mathrm{MSS}, 100 \tan \mathrm{m}^{-2}\right)$ & $47,47 \mathrm{a}$ & $52,53 \mathrm{a}$ & $54,48 \mathrm{a}$ & $45,52 \mathrm{a}$ \\
\hline $\mathrm{p}_{4}\left(3 \mathrm{MSS}, 50 \tan \mathrm{m}^{-2}\right)$ & $39,70 \mathrm{a}$ & $60,30 \mathrm{a}$ & $47,10 \mathrm{a}$ & $52,90 \mathrm{a}$ \\
\hline
\end{tabular}

Keterangan: *Data yang dianalisis adalah data hasil transformasi arcsin.

Angka-angka yang ditandai dengan huruf yang sama pada setiap kolom tidak berbeda nyata menurut Uji Jarak Berganda Duncan pada taraf nyata 5\%. 
bentuk atap. Teknik budidaya tidak berpengaruh, baik terhadap persentase bobot maupun jumlah TLP dan LP. Penaungan maupun perlakuan kombinasi teknik budidaya tidak berpengaruh terhadap persentase bobot dan jumlah dari setiap kelas kualitas (Tabel 7).

Faktor internal yang mempengaruhi laju fotosintesis daun adalah kandungan klorofil daun yang menangkap energi cahaya matahari untuk fotosintesis (Gardner et al., 1991). Salah satu pendekatan untuk mengetahui jumlah klorofil daun adalah dengan mengukur tingkat kehijauan daun. Pengamatan warna daun dengan metode Cie $\mathrm{L}^{*} \mathrm{a}^{*} \mathrm{~b}^{*}$ berturut-turut menunjukkan kecerahan, warna kromatik campuran merah-hijau, dan warna kromatik campuran biru-kuning. Data pada Tabel 8 menunjukkan bahwa naungan berpengaruh terhadap kecerahan $\left(\mathrm{L}^{*}\right)$ dan warna kromatik campuran merah-hijau $\left(\mathrm{a}^{*}\right)$, tetapi tidak berpengaruh terhadap campuran warna kromatik biru-kuning $\left(b^{*}\right)$. Namun kombinasi teknik budidaya tidak berpengaruh terhadap warna daun. Nilai $\mathrm{L}^{*}$ tanaman tanpa naungan lebih rendah yang berarti warnanya lebih gelap daripada perlakuan penaungan bentuk sungkup yang tidak berbeda dengan perlakuan penaungan bentuk atap. Selain itu, nilai a* tanaman tanpa naungan lebih negatif yang berarti lebih hijau daripada perlakuan dengan penaungan ( $\mathrm{n}_{1}$ dan $\mathrm{n}_{2}$ ).

Warna daun mempengaruhi laju fotosintesis tanaman. Semakin hijau daun tanaman, berarti semakin banyak klorofil yang terdapat pada daun dan semakin tinggi laju fotosintesis. Laju fotosintesis dipengaruhi oleh intensitas cahaya. Intensitas cahaya yang lebih tinggi menyebabkan laju fotosintesis yang lebih tinggi pula. Hal ini sesuai dengan pernyataan dari Sitompul \& Guritno (1995), bahwa laju fotosintesis meningkat pada peningkatan kuanta cahaya.

Tabel 7. Persentase bobot dan jumlah dari hasil pakcoy pada masing-masing grade kualitas

\begin{tabular}{|c|c|c|c|c|}
\hline \multirow{2}{*}{ Perlakuan } & \multicolumn{2}{|c|}{ Bobot (\%) } & \multicolumn{2}{|c|}{ Jumlah (\%) } \\
\hline & Grade A & Grade B & Grade A & Grade B \\
\hline \multicolumn{5}{|l|}{ Naungan } \\
\hline no (Tanpa naungan) & 29,42 a & $70,58 \mathrm{a}$ & 28,11 a & 71,89 a \\
\hline $\mathrm{n}_{1}$ (Sungkup kasa) & 37,67 a & 62,33 a & 22,32 a & 77,68 a \\
\hline n2 (Atap kasa) & $37,42 \mathrm{a}$ & $62,58 \mathrm{a}$ & $33,31 \mathrm{a}$ & $66,69 \mathrm{a}$ \\
\hline \multicolumn{5}{|l|}{ Teknik Budidaya } \\
\hline $\mathrm{p}_{1}\left(2 \mathrm{MSS}, 100 \tan \mathrm{m}^{-2}\right)$ & 28,99 a & $71,01 \mathrm{a}$ & $22,17 \mathrm{a}$ & 77,83 a \\
\hline $\mathrm{p}_{2}\left(2 \mathrm{MSS}, 50 \tan \mathrm{m}^{-2}\right)$ & 33,29 a & $66,71 \mathrm{a}$ & 28,94 a & 71,06 a \\
\hline $\mathrm{p}_{3}\left(3 \mathrm{MSS}, 100 \tan \mathrm{m}^{-2}\right)$ & 33,96 a & $66,04 \mathrm{a}$ & $24,21 \mathrm{a}$ & 75,79 a \\
\hline $\mathrm{p}_{4}\left(3 \mathrm{MSS}, 50 \tan \mathrm{m}^{-2}\right)$ & $43,09 \mathrm{a}$ & $56,91 \mathrm{a}$ & $36,32 \mathrm{a}$ & $63,68 \mathrm{a}$ \\
\hline
\end{tabular}

Keterangan: *Data mengalami transformasi arcsin

Angka-angka yang ditandai dengan huruf yang sama pada setiap kolom tidak berbeda nyata menurut Uji Jarak Berganda Duncan pada taraf nyata 5\%.

Tabel 8. Warna daun pakcoy pada berbagai perlakuan naungan dan teknik budidaya

\begin{tabular}{lccc}
\hline \multicolumn{1}{c}{ Perlakuan } & $\mathrm{L}^{*}$ & $\mathrm{a}^{*}$ & $\mathrm{~b}^{*}$ \\
\hline Naungan & & & $47,71 \mathrm{a}$ \\
\hline n0 (Tanpa naungan) & $66,08 \mathrm{a}$ & $-45,14 \mathrm{a}$ & $52,47 \mathrm{a}$ \\
n1 (Sungkup kasa) & $71,38 \mathrm{~b}$ & $-40,45 \mathrm{~b}$ & $48,05 \mathrm{a}$ \\
n2 (Atap kasa) & $68,86 \mathrm{ab}$ & $-40,71 \mathrm{~b}$ & $48,38 \mathrm{a}$ \\
\hline Teknik Budidaya & & & $47,68 \mathrm{a}$ \\
\hline p1 $\left(2 \mathrm{MSS}, 100 \tan \mathrm{m}^{-2}\right)$ & $70,75 \mathrm{a}$ & $-41,30 \mathrm{a}$ & $50,81 \mathrm{a}$ \\
p2 $\left(2 \mathrm{MSS}, 50 \tan \mathrm{m}^{-2}\right)$ & $69,20 \mathrm{a}$ & $-41,14 \mathrm{a}$ & $50,77 \mathrm{a}$ \\
p3 $\left(3 \mathrm{MSS}, 100 \tan \mathrm{m}^{-2}\right)$ & $68,20 \mathrm{a}$ & $-43,85 \mathrm{a}$ & $-42,11 \mathrm{a}$ \\
p4 $\left(3 \mathrm{MSS}, 50 \tan \mathrm{m}^{-2}\right)$ & $66,94 \mathrm{a}$ & & \\
\hline
\end{tabular}

Keterangan: Angka-angka yang ditandai dengan huruf yang sama pada setiap kolom tidak berbeda nyata menurut Uji Jarak Berganda Duncan pada taraf nyata 5\%. 
Perlakuan kombinasi teknik budidaya tidak berpengaruh terhadap warna daun. Pada awalnya, populasi rapat diduga dapat mengakibatkan daun saling menaungi sehingga jumlah klorofil dapat lebih sedikit daripada populasi renggang. Ternyata populasi ini masih dalam batas belum saling menaungi atau kompetisi dalam menangkap sinar matahari belum mempengaruhi jumlah klorofil.

\section{SIMPULAN}

Pengaruh penggunaan naungan kasa dan kombinasi antara umur pindah tanam bibit dan populasi tanaman hanya saling berinteraksi terhadap luas daun saat panen. Penaungan bentuk sungkup dan bentuk atap dengan kombinasi teknik budidaya populasi 50 tanaman $\mathrm{m}^{-2}$ dan umur bibit, baik pada 2 MSS maupun 3 MSS, menghasilkan luas daun lebih lebar dibandingkan dengan perlakuan lainnya.

Kasa sebagai bahan naungan mampu menurunkan intensitas cahaya matahari yang diterima tanaman pada siang hari sebesar $32 \%$ sehingga tanaman lebih tinggi, hasil panen lebih banyak 26,3 $\%$, persentase jumlah tanaman layak pasar lebih besar 34,7 \%, dan warna hijau lebih cerah.

Perlakuan kombinasi umur bibit dan populasi tidak mempengaruhi pertumbuhan, hasil, dan kualitas pakcoy yang dipanen pada umur 8 MSS tetapi penggunaan bibit umur 2 MSS dan populasi 50 tanaman $\mathrm{m}^{-2}$ menghasilkan lebih banyak daun per tanaman. Populasi 50 tanaman $\mathrm{m}^{-2}$ juga menghasilkan bobot kering pupus dan akar yang lebih tinggi, sedangkan populasi 100 tanaman $\mathrm{m}^{-2}$ memberikan hasil panen yang lebih tinggi.

\section{UCAPAN TERIMA KASIH}

Penulis mengucapkan terima kasih yang sebesarbesarnya kepada program A3 Jurusan Budidaya Pertanian Fakultas Pertanian Universitas Padjadjaran tahun anggaran 2008/2009 yang telah membiayai percobaan ini.

\section{DAFTAR PUSTAKA}

Ajwang, PO and H-J. Tantau. 2005. Prediction of the effect of insect-proof screen on climate in a naturally ventilated greenhouse in humid tropical climates. Acta Hort. 691: $449-456$.
Akyas, AM. 2000. Pertumbuhan dan hasil paprika (Capsicum annuum var. Grossum L.) pada radiasi cahaya dan konsentrasi nutrisi berbeda dalam penanaman system hidroponik. J. Agrikultura 11: 50 - 58.

Basri, H. 1989. Ekologi Tanaman. Jakarta-Rajawali Press. 136 hal.

Campen, JB. 2004. Greenhouse design applying CFD for Indonesian condition. Acta Hort. 691: 419-424.

Damanto, G, L Trotta and A Elia. 1994. Cell size, trans-plant age and cultivars effects on timing field production of broccoli (Brassica oleracea L. var. Italica Plenck) for processing. Acta Hort. 37:153 - 60.

Gardner, FP, RB Pearce and RL Mitchell. 1991. Physiology of Crop Plants (Fisiologi Tanaman Budidaya, alih bahasa oleh Susilo, H.). Universitas Indonesia Press. Jakarta. 388 hal.

Harmanto, H-J Tantau and VM Salokhe. 2006. Effect of screen sizes on performance of an adapted greenhouse for tomato production in the humid tropics. Jurnal Enjiniring Pertanian, 4: 33-40.

Mayadewi, NN dan Ari. 2007. Pengaruh jenis pupuk kandang dan jarak tanam terhadap pertumbuhan gulma dan hasil jagung manis. Agritrop. 26:153-159.

Rachman, A dan Mahfudz. 2003. Pengaruh populasi tanaman terhadap sifat agronomis serta kadar C1 daun tembakau Virginia Rajangan pada tanah vertisols di Bojonegoro. Jurnal Littri. 9:1-6.

Sitompul, SM dan B Guritno. 1995. Analisis Pertumbuhan Tanaman. Jakarta-Gadjah Mada University Press. 332 hal.

Vavrina, CS. 1998. Transplant age in vegetable crops. Hort Technology. 8:1-7.

$\mathrm{Wu}, \mathrm{ZH}$, JJ Chen and ZH Xu. (2001) Micro-climate effect of sun-shading-net and its influence on vegetable growth. J. Fujian Agric. Univ. 01-02.

Yam, KL and SE Papadakis. 2004. A Simple Digital Imaging Method for Measuring and Analyzing Color of Food Surfaces. J. Food Engineering. 61: 137-142. 